\title{
GCU
}

Glasgow Caledonian

University

University for the Common Good

\section{A spatial exploration of deprivation and green infrastructure ecosystem services within Glasgow city}

\author{
Majekodunmi, Makanjuola; Emmanuel, Rohinton; Jafry, Tahseen
}

Published in:

Urban Forestry and Urban Greening

DOI:

10.1016/j.ufug.2020.126698

Publication date:

2020

Document Version

Author accepted manuscript

Link to publication in ResearchOnline

Citation for published version (Harvard):

Majekodunmi, M, Emmanuel, R \& Jafry, T 2020, 'A spatial exploration of deprivation and green infrastructure ecosystem services within Glasgow city', Urban Forestry and Urban Greening, vol. 52, 126698.

https://doi.org/10.1016/j.ufug.2020.126698

\section{General rights}

Copyright and moral rights for the publications made accessible in the public portal are retained by the authors and/or other copyright owners and it is a condition of accessing publications that users recognise and abide by the legal requirements associated with these rights.

Take down policy

If you believe that this document breaches copyright please view our takedown policy at https://edshare.gcu.ac.uk/id/eprint/5179 for details

of how to contact us. 


\section{A spatial exploration of deprivation and green infrastructure ecosystem services within Glasgow city}

Makanjuola Majekodunmi ${ }^{1}$, Rohinton Emmanue ${ }^{1 *}$, Tahseen Jafry ${ }^{1}$

${ }^{1}$ School of Computing, Engineering and the Built Environment, Glasgow Caledonian University, Glasgow, UK

*Corresponding Author: Rohinton.emmanuel@gcu.ac.uk

\section{Abstract}

Contemporary changes to climate pose increasing hydro-meteorological risks to cities. In Glasgow, key hydro-meteorological risks include alluvial and pluvial flooding and overheating. While the need to address these risks are clear, it is equally important to tackle these in a climate just manner. Having understood the benefits Green Infrastructure (GI) can provide in tackling the impact of climate change while ensuring environmental equity for Glasgow, we attempt to assess the equitability of $\mathrm{Gl}$ distribution in Glasgow especially in relation to the potential for $\mathrm{Gl}$ to reduce vulnerability and exposure of deprived communities to climate risk in terms of flooding and overheating. We map potential of ecosystem services within urban areas to provide cooling and increase resilience to surface flooding and highlight the geographical mismatch between social deprivation and the preponderance of these ecosystem services. We explore the implications for a 'climate just transition' using $\mathrm{Gl}$ as a performance indicator.

\section{To be cited as:}

Majekodunmi M, Emmanuel R, Jafry T. 2020. A spatial exploration of deprivation and green infrastructure ecosystem services within Glasgow city, Urban Forestry and Urban Greening, https://doi.org/10.1016/j.ufug.2020.126698 


\section{Introduction}

One of the most prominent climate change adaptation approach is the promotion of green infrastructure (GI) which has been identified as capable of providing several climate change related ecosystem services such as cooling, flood protection, air pollution removal and other benefits (Emmanuel and Loconsole, 2015). Green infrastructure, such as parks, street trees, green areas, roof gardens, green walls and urban forests, also enhance human comfort, improve health and quality of life within and outside buildings and mitigate the Urban Heat Island effect - 'a phenomenon characterized by higher temperatures within a built-up urban area as compared with its rural surroundings, attributed to the modification of land surfaces and human activities within the city' (Hiemstra, Saaroni and Amorim, 2017) (Gill et al., 2007; Hall, Handley and Ennos, 2012; Middel, Chhetri and Quay, 2015; Zölch et al., 2016).. Gl on walls and roofs can reduce air pollution and overheating and play an important role in regenerating and connecting habitats (Gill et al., 2007).

While the benefits of $\mathrm{Gl}$ are well known, the relationship between $\mathrm{Gl}$ type, its spatial arrangement, landscape and temperature is quite complex and would require further understanding to be able to provide location specific estimates (Duncan et al., 2019). Besides, the question of its usefulness in identifying inequity as well as highlighting potential ecosystem services within urban areas remains un-answered especially in relation to the possibility of Gl highlighting these linkages. In this connection, the city of Glasgow presents a unique study area since it experiences significant inequality mostly associated with economic decline and is susceptible to sub-surface flooding and other climatic impacts such as rising sea levels and temperatures. It is likely that climate change would increase the current inequality and thus an urgent need exists for an equitable and just mechanisms to reduce vulnerability and increase adaptability in an affordable and more effective way (ASC, 2016c; SNIFFER, 2017).

\section{Background}

Climate change in Glasgow Between 1961 and 2004, the temperature of Scotland rose by $1^{\circ} \mathrm{C}$ and average temperatures will have risen more by 2050 (Adaptation Scotland, 2017). While a warmer climate can make people spend more time outdoors and adopt a healthier outdoor-oriented lifestyle, with reduced cold related deaths in winter, the current housing infrastructure may not perform effectively under these temperatures and cities like Glasgow (the largest city in Scotland) is likely to be negatively affected by the Urban Heat Island phenomenon, due to effective trapping of solar radiation by the arrangement of buildings, air pollution, high energy use and associated wasted heat as well as an approximate $200 \mathrm{Ha}$ increase in impermeable surfaces between 2008 2015 (ASC, 2016a; ClimateXChange., 2016). In addition, the river Clyde which flows through the 
heart of Glasgow city (Figure $1 \mathrm{a}$ and b) poses significant risk to $68 \%$ and $32 \%$ of the total city area from surface water and coastal flooding respectively due to climate change as sea levels are expected to rise by approximately $70 \mathrm{~cm}$ before the end of the century, consequently impacting on homes, businesses and restricting accessibility (SEPA, 2015; Adaptation Scotland, 2017).

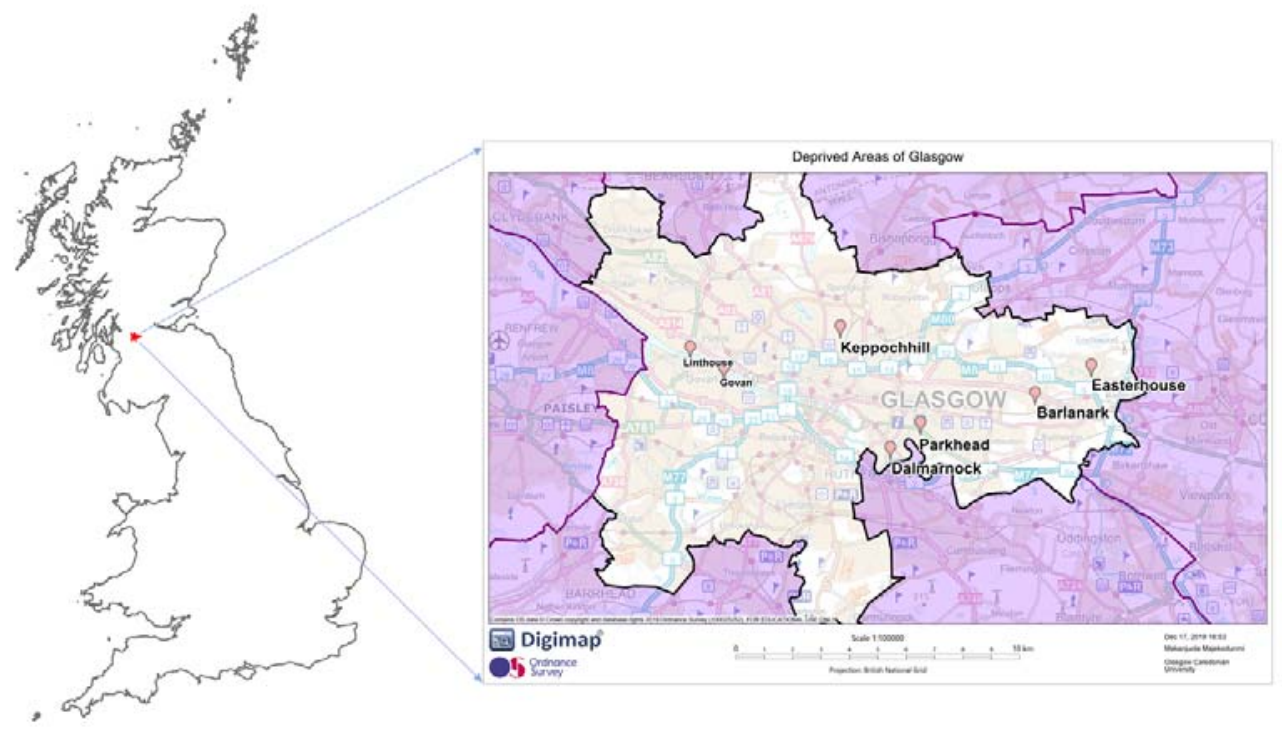

Figure 1a: Map of UK showing Glasgow City

Note: Place names discussed in the text are shown within the city limits

SOURCE: Based on OS Open Data

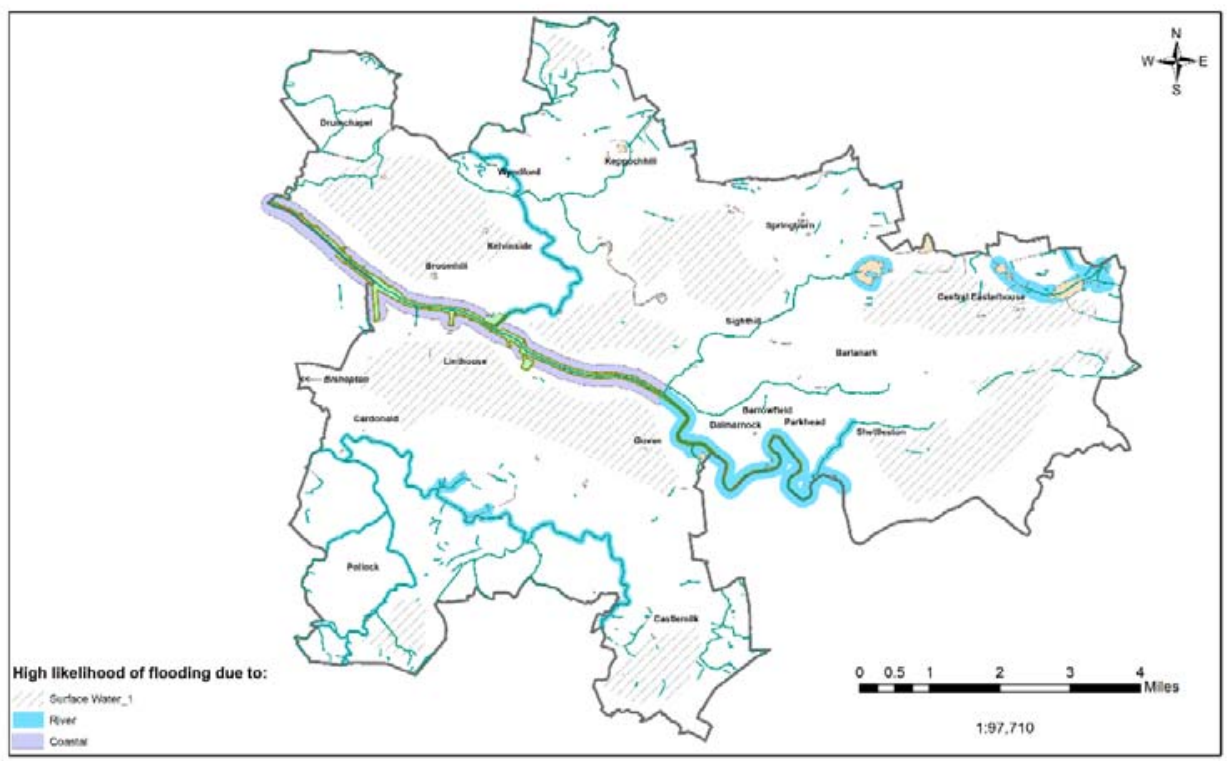

Figure 1b: Flood-prone areas of the city of Glasgow

Source: Redrawn from SEPA data available at (http://map.sepa.org.uk/floodmap/map.htm) 
Additionally, technical findings suggest that severe weather conditions to the south and west of the Firth of Clyde, combined with high tidal conditions, could lead to water levels rising above the Quay walls in the city center (SEPA, 2015).

At the same time, communities within Glasgow city such as Parkhead West and Barrowfield, Barlanark, Central Easterhouse, Dalmarnock, Govan and Linthouse, Keppochhill and Wyndford have constantly experienced deep-rooted deprivation since 2004 (Scottish Government, 2016b). This poses a unique problem as these communities are likely to be heavily impacted in the event of flooding incidents (damage to property, accessibility restrictions and service disruptions) or a rise in temperatures (mortality and morbidity increases, thermal discomfort) (ClimateXChange, 2016).

Although most of the areas within the Glasgow region have been identified as being potentially vulnerable to various forms of flooding (Glasgow City Council, 2010), this paper will focus on Glasgow city which is the largest urban area in Scotland and has a fast growing economy which attracts both industries and, tourists and is famous for hosting international events (ASC, 2012). History of severe weather incidents for Glasgow city

During the $18^{\text {th }}$ and $19^{\text {th }}$ century, a series of flooding incidents occurred causing hazard and damages to people and properties, but this was prior to the Clyde being canalised and widened to the south (SEPA, 2015). While this had greatly reduced incidents of flooding recent years have seen an increase in flooding events.

Between 1991 and 2009, a total of 161 weather events were reported in Glasgow, with the largest number occurring in 2002, 2003 and 2008 (Table 1). Fog, heavy rain and heavy rain/high winds were the three most common severe weather types (Table 2 ) inflicting severe damage to infrastructure and buildings (Table 3) (Glasgow City Council, 2010). Notable precipitation-related severe weather events between 2010 and 2019 include: Prolonged snow cover in December 2010 with mean maximum temperature of $1.7^{\circ} \mathrm{C}$ and mean minimum temperature of $-5.1^{\circ} \mathrm{C}$; Disruptive snow between December 2017 and March 2018 with a maximum depth of $46 \mathrm{~cm}$; Severe gales $\left(8^{\text {th }}\right.$ December 2011, $3^{\text {rd }}$ January 2012, $9^{\text {th }}$ January 2015, $6^{\text {th }}$ August 2016, $14^{\text {th }}$ June 2018 brought by storm Hector, $20^{\text {th }}$ September 2018 brought by storm Ali and $12^{\text {th }}$ March 2019 brought by storm Gareth); Heavy rains with $304.2 \mathrm{~mm}$ and $367.0 \mathrm{~mm}$ of rain recorded in Bishopton for November and December 2015; Extreme heat with maximum temperature of $31.9^{\circ} \mathrm{C}$ recorded in Bishopton on the $28^{\text {th }}$ of June 2018 , currently exceeding previous maximum temperature of $31.2^{\circ} \mathrm{C}$ recorded in Abbotsinch(Met Office, 2019) . 
Various agencies including the Scottish Environmental Protection Agency, Scottish Water, and The Metropolitan Glasgow Strategic Drainage Partnership have made significant investments and progress, especially in identifying and mapping potential surface water vulnerable areas, reducing flood risks for approximately 7000 properties and a drop in flooding incidents from main sewers by 17\% since 2010 (ASC, 2016a). This was possible through concrete actions such as the maintenance of flood protection schemes, flood forecasting and issuance of flood warnings, raising awareness of flood risk and actions that could be taken such as preparing a flood plan and flood kit, undertaking insurance, maintenance of water courses and public sewer network by the local authority, providing better emergency response by coordinating with regional and local resilience partnerships, adopting planning policies that avoid development in areas with medium to high likelihood of flooding (SEPA, 2015). However, there are still over 9000 properties with at least a 1 -in-200 chance of surface water flooding and 300 residential properties with a 1-in-10 chance of being flooded (ASC, 2016a).

Table 1: Number of identified severe weather events between 1999 and 2009 Source: Glasgow City Council (2017)

\begin{tabular}{|c|c|}
\hline \multicolumn{2}{|c|}{$\begin{array}{c}\text { Number of identified severe weather events } \\
\text { between } 1999 \text { and } 2009 \\
\text { Year }\end{array}$} \\
\hline 1999 & 3 \\
\hline 2000 & 7 \\
\hline 2001 & 13 \\
\hline 2002 & 29 \\
\hline 2003 & 23 \\
\hline 2004 & 13 \\
\hline 2005 & 11 \\
\hline 2006 & 18 \\
\hline 2007 & 13 \\
\hline 2008 & 22 \\
\hline 2009 & 9 \\
\hline Total & 161 \\
\hline
\end{tabular}

Table 2: Types of severe weather events recorded for Glasgow Source: Glasgow city Council (2017)

\begin{tabular}{|c|c|}
\hline \multicolumn{2}{|c|}{ Severe weather events recorded } \\
\hline Weather Type & $\mathbf{1 9 9 9}$ and 2009 (\%) \\
\hline Fog & 20 \\
\hline Heavy Rain & 18 \\
\hline Ice & 7 \\
\hline Snow & 3 \\
\hline Heavy Rain/ Heavy winds & 15 \\
\hline High / unreasonably high temperatures & 11 \\
\hline Low/ unreasonably low temperatures & 10 \\
\hline Wind & 6 \\
\hline Other & 10 \\
\hline
\end{tabular}


Table 3: Impact of severe weather events between 1999 and 2009 Source: (Glasgow City Council, 2017)

\begin{tabular}{|c|c|c|}
\hline Type of impact & No & $\begin{array}{c}\text { Percentage } \\
(\%)\end{array}$ \\
\hline Damage to infrastructure & 94 & 50.5 \\
\hline Damage to buildings & 22 & 11.8 \\
\hline Flood/Surface flooding & 17 & 9.1 \\
\hline Positive impact & 9 & 4.8 \\
\hline Injury/Crime & 7 & 3.8 \\
\hline Power failure/cut & 3 & 1.6 \\
\hline Change in lifestyle/working conditions/change in processes & 13 & 7.0 \\
\hline Damage to environment/changes in biodiversity/vegetation & 9 & 4.8 \\
\hline Damage to health/vulnerable groups & 5 & 2.7 \\
\hline Other & 7 & 3.8 \\
\hline Total & 186 & 100 \\
\hline
\end{tabular}

\subsection{Overheating potential within Glasgow city}

There is no internationally accepted definition of overheating due to its variation based on the local and regional climatic conditions; what may be considered normal in a particular country, may be deemed excessive in another country (Dengel et al., 2016). The Chartered Institution of Building Services Engineers (CIBSE) considers overheating to be that temperature at which an individual feels reasonably comfortable to have been sufficiently exceeded long enough to make them feel unacceptably uncomfortable (Lawrence-Race, 2010). The WHO recommended 'safe temperature' ranges from $18-22^{\circ} \mathrm{C}$ (World Health Organization, 2007). The Standard Assessment Procedure (SAP) - UK government's approved means of assessing energy and environmental performance of buildings defines overheating risk as 'slight' when air temperatures are between $20.5^{\circ} \mathrm{C}$ and $22^{\circ} \mathrm{C}$; 'medium' $=22^{\circ} \mathrm{C}-23.5^{\circ} \mathrm{C}$ and 'high' $>23.5^{\circ} \mathrm{C}(\mathrm{ZCH}, 2015)$. An internal temperature of $25^{\circ} \mathrm{C}$ is an important health threshold identified in the UK government's Housing Health and Safety Rating System (HHSRS) (ODPM, 2006).

While most of the evidence for overheating in the UK to-date come from England, there is increasing concern regarding overheating in the West of Scotland. McLeod, Hopfe, and Kwan (2013) highlighted the overheating risk in super-insulated buildings in Scotland and other Northern European countries. Morgan, at al. (2015) suggest that there is increasing evidence of overheating already occurring in Scotland. Based on recent fieldwork in Scotland Morgan et al (2017) showed that $54 \%$ of the houses they had studied experienced overheating for at least six months during the year.

Of the 36 recommendations made by the Adaptation Sub-Committee (ASC) of the UK Committee on Climate Change to the Scottish Government in 2015, eleven were considered priority and overheating was among these. However, the Government rejected the ASC's recommendation 
being 'mindful of other commitments, for example to reduce net regulation on homebuilders' (Committee on Climate Change, 2017). Given this, there are a few incentives for developers to ensure they mitigate over heating risk in new buildings, and the health implication of overheating eventually falls on the occupier of these buildings (ASC, 2017). At the neighbourhood and settlement scale, although the National Planning Policy Framework requires local planning authorities to adapt strategies to climate change, including the provision and protection of urban green space, they fail to specifically mention planning measures to manage risk from heat. With average temperatures increasing across Scotland, and a 16\% increase in the population over the age of 75 between 2007 and 2017 vulnerable people, including the elderly and those who cannot afford the mitigation costs, will be exposed to increased overheating risk (ASC, 2016b; Committee on Climate Change, 2017).

Overheating has the potential to decrease the productivity, safety and comfort of workers in various occupations. Currently, heat related deaths in the UK are averaged at $2000 \mathrm{yr}^{-1}$ but this is expected to increase by $250 \%$ by 2050 and 500\% by 2080 (ASC, 2016d, 2016a). Across Europe, a recent survey found that 411 out of 571 southern and central European cities are vulnerable to heatwaves, with some experiencing intense heatwaves of at least $10^{\circ} \mathrm{C}$ (Guerreiro et al., 2018). These recent trends should serve as an important reminder of the need to act and provide a socially-just response to climate change for all, and especially for the most vulnerable.

\subsection{The role of $\mathrm{Gl}$ in climate change mitigation}

The European Commission defined GI or greenspace as "the use of ecosystems, green spaces and water in strategic land use planning to deliver environmental and quality of life benefits. It includes parks, open spaces, playing fields, woodlands, wetlands, road verges, allotments and private gardens. Green infrastructure can contribute to climate change mitigation and adaptation, natural disaster risk mitigation, protection against flooding and erosion as well as biodiversity conservation" (The Scottish Government, 2011, page 7). Gl also includes blue infrastructure (urban drainage, swales, wetlands, rivers and other water courses) and each individual element of Gl can serve a useful GI purpose without being connected (The Scottish Government, 2011) but provide further combined benefits when Gl elements are linked together to form 'green networks' (The Scottish Government, 2011).

GI as a climate change mitigation approach is well known (Carter et al., 2018; Gill et al., 2007; Hall et al., 2012). Emmanuel and Loconsole (2015) showed that a $20 \%$ increase in $\mathrm{Gl}$ above the current level could reduce surface temperatures by approximately $2^{\circ} \mathrm{C}$, thereby providing an improved quality of life both in public places. GI can also tackle sub-surface flooding and protect homes and businesses, which has been identified as a major issue within Glasgow city by SEPA (2015). The effects of 
flooding downstream can also be mitigated by GI by serving as wetlands which hold water, slow down run-off and reduce pressure on drainage system (Clydeplan, 2015).

For flood mitigation purposes, GI could be applied in various ways, for instance, the presence of street and park trees could provide tree canopy cover that act was water interceptors by slowing down the progress of water towards water courses before it hits the ground. This has been successfully applied in Santa Monica, California with an estimated annual reduced storm water treatment and flood control costs of approximately $\$ 110,000$ (Xiao and McPherson, 2003). Blue infrastructure such as lakes, reservoirs or lochs could act as accessible storage facilities that could be utilised for other purposes such as tourism, recreation and promoting ecological bio-diversity and GI on peaty soils, wetlands, woodlands and orchards could aid in reducing runoff towards water courses (Carter et al., 2018). Also, strategically placed semi-natural grasslands, heathlands, moorlands, scrublands, wetlands and woodlands could aid in slowing down flood flows and enhance flood storage (Thomas and Nisbet, 2007; Carter et al., 2018)

In addition to climate change mitigation, GI can also provide social benefits such as improving the health and well-being of communities that utilise accessible greenspace and networks (Hislop and Corbett, 2018); promote biodiversity and the environment by linking diverse habitats and reducing human impact on the environment; create stronger communities where people can come together, make living in such areas sustainable and empowering the local communities to take ownership of safe and attractive places; and provide economic development, as vibrant communities will attract business investment and tourists (GCVGreenNetwork, 2014).

GI can also be viewed as a nature-based solution capable of providing mitigation and adaptation to the impact of climate change, air pollution and other environmental ills associated with urbanisation as it may encourage the young to spend less time on the screen and encourage the old to take walks outside consequently lowering asthma, child obesity and a general improvement in the health and wellbeing of residents (Kabisch and van den Bosch, 2017).

At the same time, an increase in population could lead to the development of urban planning policies aimed at converting $\mathrm{Gl}$ space into residential lands consequently leading to an unequal distribution of Gl within the city (Kabisch and Haase, 2014). In Glasgow, field reconnaissance showed residential infrastructure being developed in various pockets around the city which were previously green spaces.

In addition, an equitable distribution of high quality and safe $\mathrm{Gl}$ in ensuring a healthy urban community was emphasised as by Kabisch and van den Bosch (2017). Given historic legacies in cities 
in terms of unequal GI provision several cities have adopted threshold values in ensuring that city residents have a certain amount of green space within their vicinity (for example, Berlin - Keeley, 2011; Kabisch and Haase, 2014).

\subsection{Role of GI in achieving a climate-just transition}

Issues around equity and justice are intrinsic to the management of climate change. As acknowledged by the IPCC in its $5^{\text {th }}$ Assessment Report, 'mitigation and adaptation raise issues of equity, justice, and fairness, and are necessary to achieve sustainable development' (IPCC, 2014). While some of the technologies and approaches to climate change mitigation may not 'necessarily pass a benefit-cost test that takes account of the range of risks and side effects' (IPCC, 2014) a GIbased approach may not carry such risks (Heckert and Rosan, 2018). As such, GI could play a role in achieving climatically equitable adaptation to climate change as well as in highlighting areas where such adaptation are needed. This has received some attention in recent years. Ferguson et al. (2018) explored the distribution of GI in Bradford, UK. They found that while GI density was highest in low socioeconomic areas accessibility was highest in high socioeconomic areas. The issue of GI accessibility in Europe was also highlighted by O'Brien et al. (2017). Distance and distribution of Gl, large road infrastructure, lack of adequate recreational infrastructure and quality of GI, lack of information and knowledge on rights of access, cultural norms, safety and confidence issues could play a role in $\mathrm{Gl}$ accessibility (O'Brien et al., 2017). Thus, care is needed in ensuring the benefits of GI-based climate resilience are equitably available across socioeconomic, ethnic and cultural subgroups (Meerow and Newell, 2019). Our decision to adopt a climate-just approach is based on this observation, since most communities affected by climate change are not adequately catered for, nor have the social dimensions of vulnerability to climate change been sufficiently captured using existing adaptation policies (Lindley et al., 2011). Various frameworks for climate justice have been developed aimed at assessing the uneven socio-spatial vulnerability and climate disadvantage of these communities across the United Kingdom (Lindley et al., 2011). GI-based tools are one such example (e.g. Heckert and Rosen, 2018 who incorporated a GI equity index with the StormWISE model) and the present work aims to add to this growing area of research.

\section{Materials and methods}

Our focus is on the distribution of ecosystem services provided by Gl in terms of flood mitigation and overheating prevention in Glasgow and their links to socioeconomic conditions of local areas. We attempt to assess this using two data sets: Scottish Index of Multiple Deprivation (SIMD) and GI data. 


\subsection{Scottish Index of Multiple Deprivation (SIMD)}

SIMD data is Scotland's official means of identifying the most deprived areas in Scotland and was first produced in 2004 with the latest version produced on the 28 January 2020 (Scottish Government, 2020). Data on income, employment, education, health, access to services, crime and housing for the whole of Scotland are weighted and combined to create an overall SIMD score which is then ranked from 1 (most deprived) to 6,976 (least deprived) (Scottish Government, 2020).

Details of the method are available at Scottish Govt (2016) and data sources could be accessed from: https://www.gov.scot/collections/scottish-index-of-multiple-deprivation-2020/

Raw SIMD data was obtained (https://www.gov.scot/publications/scottish-index-of-multipledeprivation-2020-indicator-data2/) showing the whole of Scotland. SIMD data for our study area (Glasgow City) was extracted from the above dataset and the areas with the lowest 10\% SIMD score for Glasgow city was highlighted using ArcGIS attribute tool and raster calculator and the output can be seen in Figure 2.

Glasgow City Most Deprived 10\%

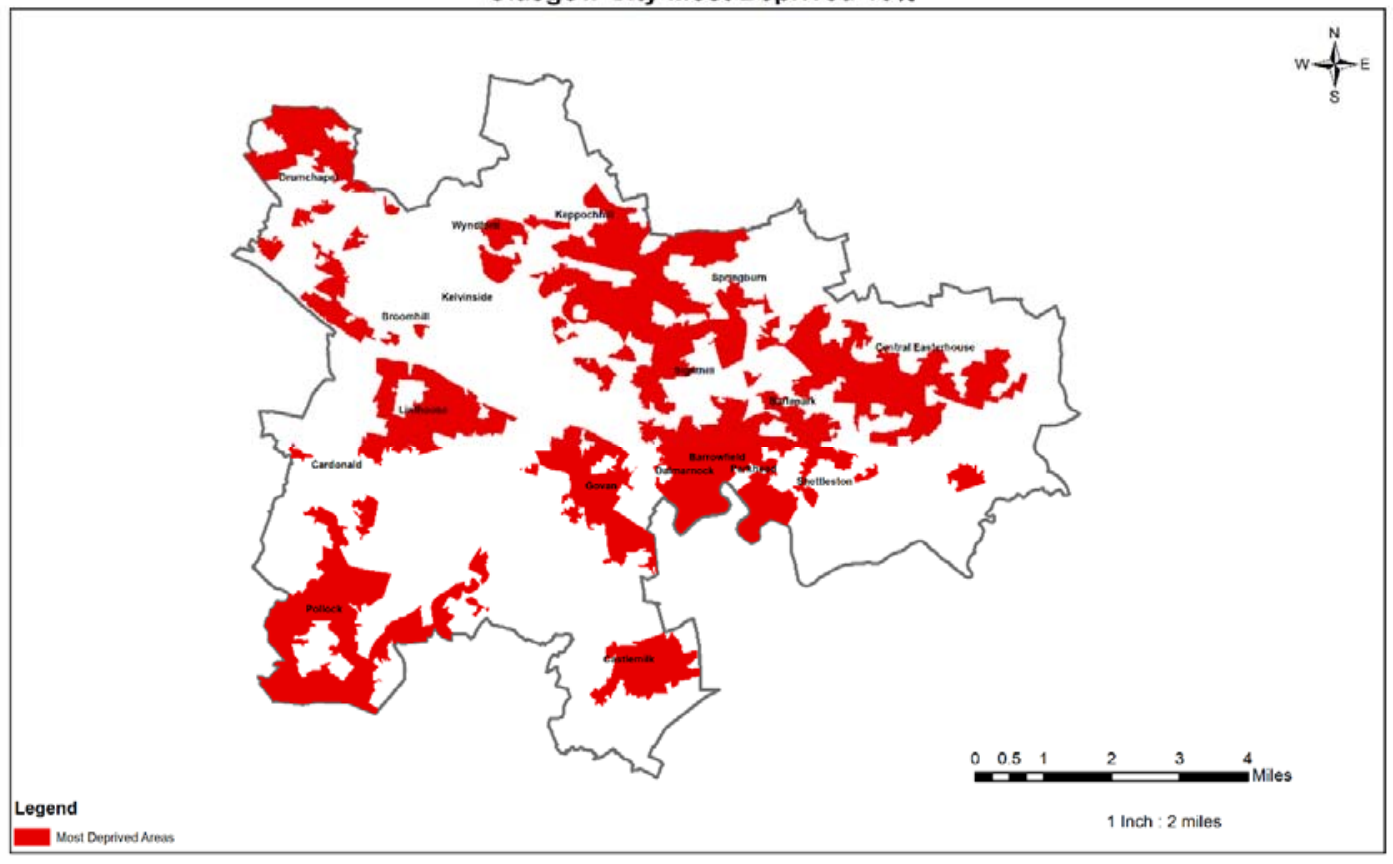

Figure 2: The most deprived areas within the city of Glasgow as identified by SIMD 


\subsection{Green Infrastructure data}

The Planning Advice Note (PAN) 65 is the principle means of gathering spatial data on GI distribution in Scotland. PAN65 refers to 'open space' as any greenspace consisting of any vegetated land or structure, water, path or geological feature within settlements, civic space, market, paved or hard landscaped areas with a civic function (The Scottish Government, 2008)

Although, the PAN 65 definition of 'open space' consists of green and hard non-permeable civic space elements, our research will focus on space termed 'Green Infrastructure' which is mainly the green and blue natural features.

The various Gl/open space types have been elaborated in Table 4:

\begin{tabular}{|c|c|}
\hline Open Space & Description \\
\hline Public parks and gardens & $\begin{array}{l}\text { These are areas of enclosed land, designed, } \\
\text { constructed managed and maintained as a public } \\
\text { park or garden }\end{array}$ \\
\hline Private gardens or grounds & $\begin{array}{l}\text { These are normally enclosed lands, associated } \\
\text { with a house or school and utilised privately }\end{array}$ \\
\hline Amenity greenspace & $\begin{array}{l}\text { Landscaped areas usually separating buildings or } \\
\text { land use for environmental, visual or safety } \\
\text { reasons and utilised for informal or social } \\
\text { activities }\end{array}$ \\
\hline $\begin{array}{l}\text { Play space for children and } \\
\text { teenagers }\end{array}$ & $\begin{array}{l}\text { These are safe and accessible areas for children } \\
\text { to play and mostly associated with houses }\end{array}$ \\
\hline Sports areas & $\begin{array}{l}\text { These are large flat areas of grassland or } \\
\text { synthetic surface used generally for various } \\
\text { sporting activities }\end{array}$ \\
\hline Green corridors & $\begin{array}{l}\text { These are routes such as canals, river corridors } \\
\text { and old railway lines linking different areas } \\
\text { within a city or surrounding country sides or } \\
\text { parks and mostly used for walking, cycling or } \\
\text { horse riding }\end{array}$ \\
\hline Natural/semi-natural green space & $\begin{array}{l}\text { These are areas that are undeveloped or } \\
\text { previously developed with natural or introduced } \\
\text { habitats or colonized by vegetation and wildlife } \\
\text { including woodland and wetland areas }\end{array}$ \\
\hline Civic space & $\begin{array}{l}\text { These are squares, streets and water fountains } \\
\text { comprised of mostly hard landscaped surface } \\
\text { and used in making connections for pedestrians } \\
\text { and wildlife }\end{array}$ \\
\hline Burial grounds & This includes churchyards and cemeteries \\
\hline Other functional greenspace & $\begin{array}{l}\text { Other types of open space as required by the } \\
\text { local authority }\end{array}$ \\
\hline
\end{tabular}


Under PAN 65, there is an obligation on local authorities in Scotland to produce and update GI data.

We obtained the GI data from the Glasgow City Council as a series of ArcGIS files (see example on Figure 3).

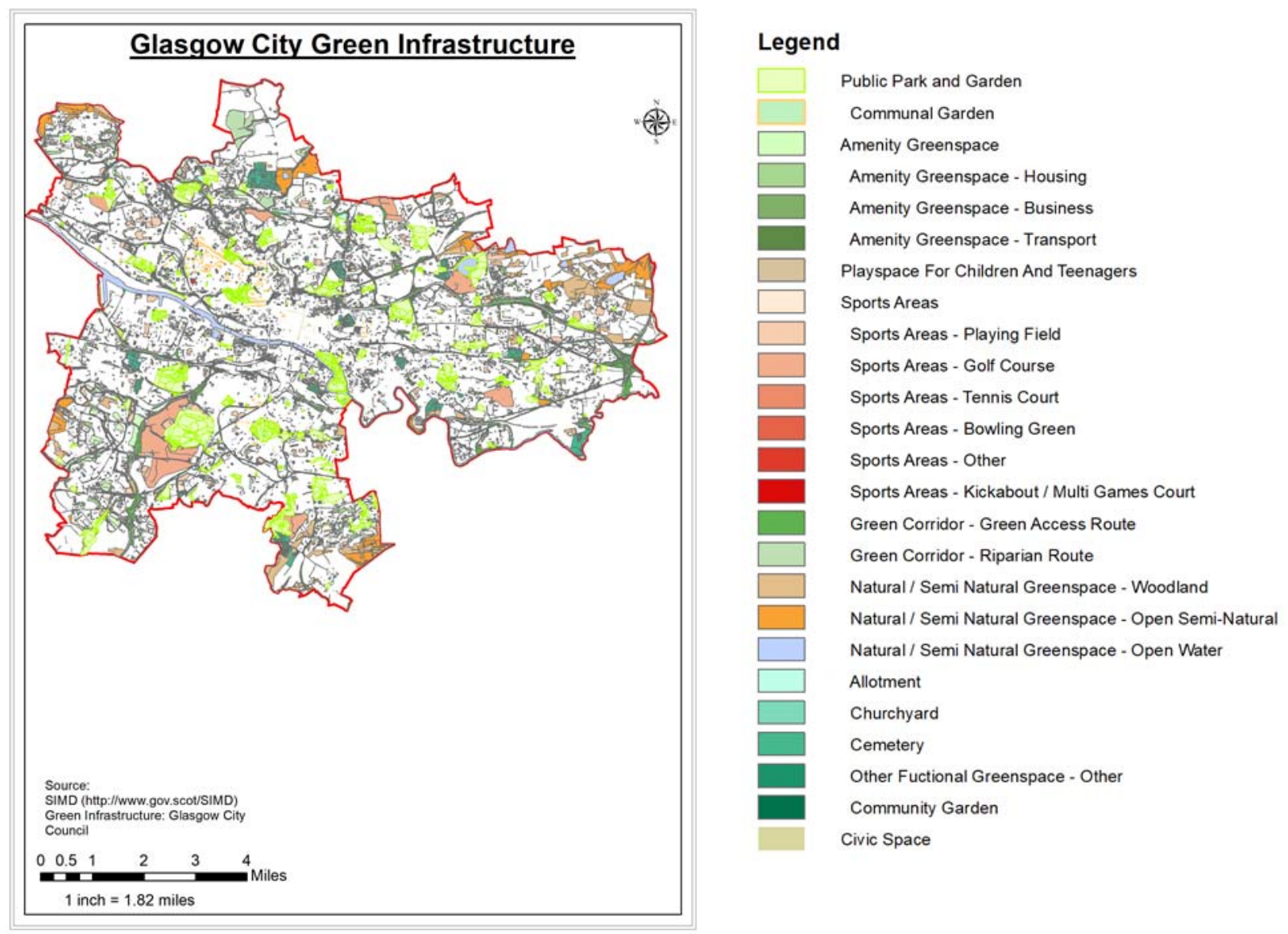

Figure 3: Glasgow City Green and Blue Infrastructure

Source: PAN65 Data provided by Glasgow City Council

Having obtained the SIMD data (Figure 2) and the GI data (Figure 3) in .shp and .Ipk files respectively, these were analysed in ArcGIS. In order to ascertain the equitability of GI within these deprived areas, we first calculated the total extent of the most deprived areas (5,255 ha) within Glasgow city $(17,645 \mathrm{ha})=30 \%$. We thus hypothesized that $30 \%$ of all Gl in Glasgow city located within the most deprived areas would represent an 'equitable distribution' of GI. Further analysis was done by calculating the shape area of each GI within the SIMD deprived area and the rest of Glasgow city using the analyst tool in ArcGIS, and the percentage difference was run for each Gl type to identify threshold values of various types of GI within the city limits (Table 5); the extract tool in ArcGIS was used to output these results. This was done to ascertain the equitability of GI within deprived areas (See 'Results' Section 'a' below). Thereafter a second part of the analysis was carried out to estimate 
the potential of GI to provide cooling ('Results' Section 'b' below) and mitigate sub-surface flooding ('Results' Section ' $c$ ' below). Finally, these were linked to areas of deprivation to ascertain the equitability of ecosystem services provided by GI.

\section{Results}

A review of the extracted SIMD data in ArcGIS showed that the lowest 10\% SIMD data for Glasgow city ranked from 2 -693. This figure when compared with Scotland's SIMD ranking of 1 (most deprived) to 6976 (least deprived) (Scottish Government, 2016b) indicates that Glasgow city is at the lower end of the scale and visual observation of Fig. 2 showed a spatial distribution of deprived areas concentrated within the central and north eastern parts of the city.

\subsection{Equitability of Green Infrastructure}

Using ArcGIS, we calculated the total area (ha) of each individual GI type for Glasgow city and deprived areas respectively and derived the percentage difference of each GI (Table 5)

Table 5: Green Infrastructure expectation

\begin{tabular}{|c|c|c|c|c|c|c|}
\hline $\mathrm{GI}$ & $\begin{array}{l}\text { SIMD } \\
\text { Deprived } \\
\text { areas (Ha) }\end{array}$ & $\begin{array}{l}\text { GI within } \\
\text { SIMD } \\
\text { Area (\%) }\end{array}$ & $\begin{array}{l}\text { Glasgow } \\
\text { City (Ha) }\end{array}$ & $\begin{array}{l}\text { Gl within } \\
\text { Glasgow } \\
\text { City (\%) }\end{array}$ & $\begin{array}{l}\text { Threshold } \\
(30 \%)^{*}\end{array}$ & $\begin{array}{l}\mathrm{Gl} \\
\text { Expectations }\end{array}$ \\
\hline $\begin{array}{l}\text { Public Park and } \\
\text { Garden }\end{array}$ & 188 & 3.5 & 1,009 & 5.7 & 18.6 & Not Met \\
\hline $\begin{array}{l}\text { Community } \\
\text { Garden }\end{array}$ & 0.14 & 0.003 & 17 & 0.096 & 0.8 & Not Met \\
\hline $\begin{array}{l}\text { Amenity Green } \\
\text { Space }\end{array}$ & 428 & 8.14 & 920 & 5.21 & 46.5 & Exceeded \\
\hline $\begin{array}{l}\text { Play space for } \\
\text { Children and } \\
\text { Teenagers }\end{array}$ & 9 & 0.17 & 20 & 0.11 & 45 & Exceeded \\
\hline Sport Areas & 251 & 4.8 & 904 & 5.12 & 27.8 & Not Met \\
\hline Green Corridor & 211 & 4 & 828 & 4.7 & 25.5 & Not Met \\
\hline $\begin{array}{l}\text { Natural/Semi- } \\
\text { Natural Green } \\
\text { Space }\end{array}$ & 188 & 3.6 & 1,220 & 6.9 & 15.4 & Not Met \\
\hline $\begin{array}{l}\text { Other } \\
\text { functional } \\
\text { Green Space }\end{array}$ & 125 & 2.4 & 300 & 1.7 & 41.7 & Exceeded \\
\hline Civic Space & 10 & 0.19 & 21 & 0.12 & 47.6 & Exceeded \\
\hline
\end{tabular}

* See text for the rationale for the threshold

In order to find out if each GI type met our hypothesis of $30 \%$ equitable distribution within deprived area. The percentage difference between GI in deprived areas and Glasgow city under each GI 
category was then compared (for example, amenity green space within deprived areas ( $428 \mathrm{ha}$ ) divided by total amenity green space within Glasgow city $(920 \mathrm{ha})=46.5 \%)$ exceeding our hypothesised threshold for GI (amenity green space) located within deprived area. The various GI types (Table 5) give us a mixed representation of Gl within the study area as 5 out of 9 Gl types for Glasgow city did not meet our Gl expectation.

Although, from visual observation of the maps and attribute table in ArcGIS, public parks and garden look well distributed across Glasgow city, closer observation showed this was deficient in deprived areas and was mainly concentrated around the north-eastern part of Glasgow.

For communal gardens, observations showed concentrations around the north western and central parts of the city. However, only one communal garden was located within the SIMD deprived area.

Amenity green space and play space for children and teenagers also showed clear signs of being well distributed within the study area from visual observations, and exceeded our Gl expectations for the region by ( $46.5 \%$ - 30\% threshold) 16.5 and (45\% - 30\%) 15\% respectively.

Sport areas showed clear signs of being well distributed across the city, but fell short of our expectation by $(27.8 \%-30 \%)-2 \%$. Most of the large sport areas were outside the SIMD deprived areas and were identified as golf courses.

Green corridor did not meet our GI expectation within the SIMD deprived area, but this is understandable as most of the identified green corridors were along major roads which were either outside or sharing boundaries with SIMD deprived areas, and a similar trend was also observed for the natural/semi-natural green space.

The distribution of other functional greenspace within Glasgow city was fair, and exceeded our expectation within SIMD deprived area by $(41.7 \%$ - 30\%) $11.7 \%$. However, most of the other functional green space within the SIMD deprived areas are cemeteries, apart from a few allotments such as Shettleston, Springburn and others. This poses another significant equity problem, as not many people may have use for a cemetery apart from burying or remembering a loved one.

Civic space also exceeded our expectation within the SIMD deprived area by (47.6\% - 30\%) $17.6 \%$. However, this was mostly concentrated in the central part of Glasgow city and may predominantly made up of semi-permeable materials utilised by pedestrians. Also, the nature of the surface might not be able to mitigate sub-surface flooding or overheating.

Thus, GI is not equitably distributed within the most deprived areas, although the overall provision of $\mathrm{Gl}$ in the city is high. Furthermore, we can further argue that its distribution is not equitable, 
especially when we consider that some of these large GI types within deprived areas capable of providing high cooling may only appeal to a selected population, as such grounds are mostly associated with performing burial rites and visits or located in private grounds and not available for public use.

\subsection{Green Infrastructure cooling potential estimation for Glasgow city}

In order to estimate the cooling potential for Glasgow city, we hypothesized that the cooling provided by the various $\mathrm{GI}$ types depends on the type of $\mathrm{Gl}$ and the extent of $\mathrm{Gl}$; greater the $\mathrm{GI}$ extent, the greater its potential to provide cooling. The methods proposed by Zardo et al, (2017), together with the methodology used by green area indices (such as those by Keeley (2011)) were used to group Gl types into three broad cooling potential classes by assigning weight factors to each individual GI type based on their shape area and cover type (Table 6). A similar approach was applied to the Urban GI of Bradford, UK, by Ferguson et al., (2018) where green space quality was measured using the natural environment scoring tool. However, this study excluded green spaces that were smaller than 2 ha and not accessible to the public and factored street tree density in their analysis.

\begin{tabular}{|c|c|c|c|}
\hline \multirow[t]{2}{*}{ Types of GI } & \multirow{2}{*}{$\begin{array}{c}\text { Potential Cooling } \\
\text { Effect }\end{array}$} & \multicolumn{2}{|c|}{ Factor } \\
\hline & & $<2 \mathrm{Ha}$ & $>2 \mathrm{Ha}$ \\
\hline Public Parks and Gardens & \multirow{4}{*}{ High } & \multirow{4}{*}{0.80} & \multirow{4}{*}{1.00} \\
\hline Communal Gardens & & & \\
\hline Amenity Green Space & & & \\
\hline $\begin{array}{l}\text { Natural/Semi-natural Green } \\
\text { Space }\end{array}$ & & & \\
\hline $\begin{array}{l}\text { Play space for children and } \\
\text { teenagers }\end{array}$ & \multirow{4}{*}{ Medium } & \multirow{4}{*}{0.40} & \multirow{4}{*}{0.60} \\
\hline Sport areas & & & \\
\hline Green Corridor & & & \\
\hline Other functional green space & & & \\
\hline Civic Space & Low & - & 0.20 \\
\hline
\end{tabular}

The weighted GI layers were then merged to produce a cooling potential map using ArcGIS (Figure 4). 


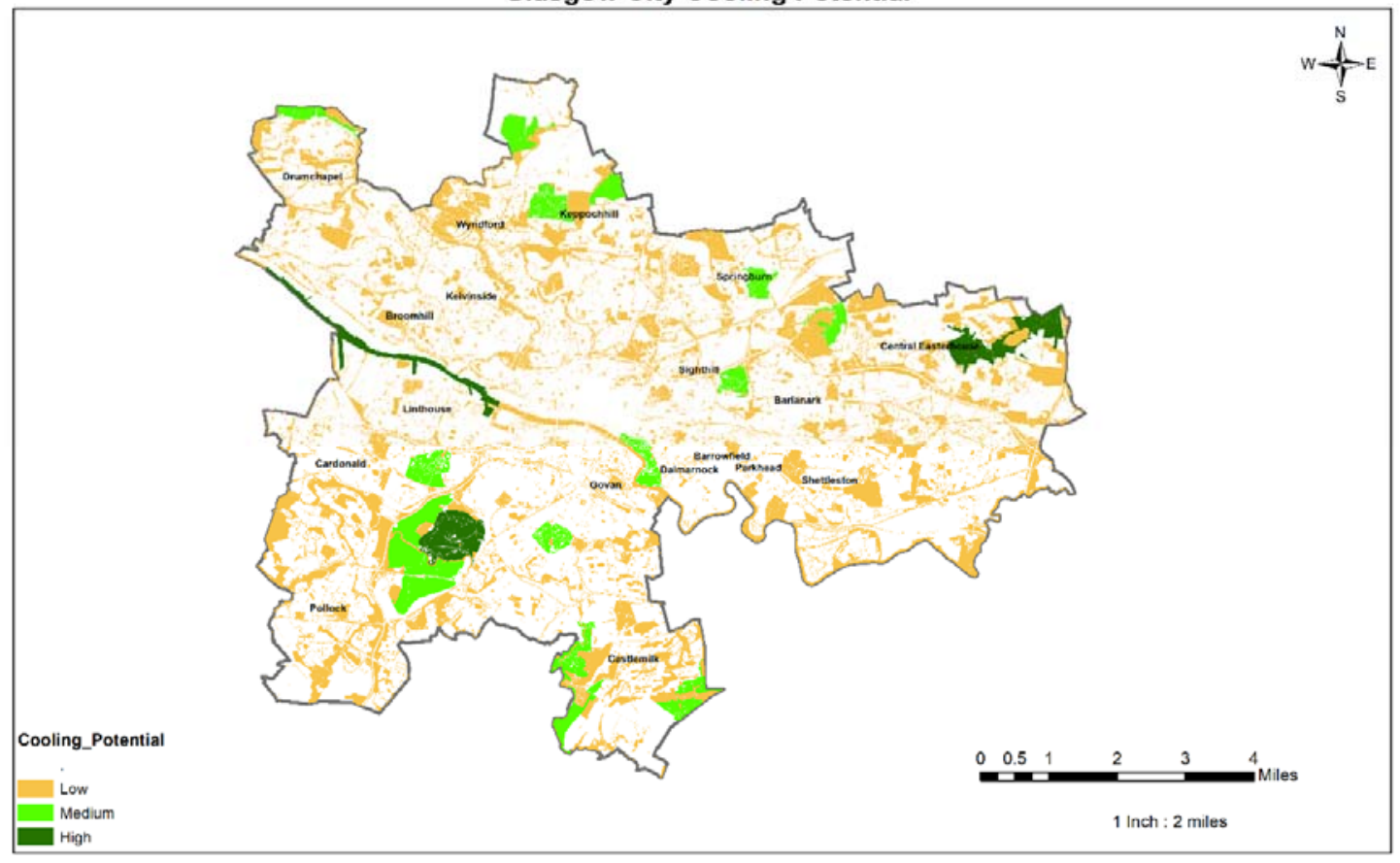

Figure 4: Cooling Potential Map of Glasgow City

Note: See Table 6 for weightage factors

In order to extract the cooling potential available to the $10 \%$ most deprived areas cooling potential data was clipped to show only those areas that fell within the bottom 10\% of SIMD zones (Figure 5). An overview of the cooling potential for Glasgow city showed a mix of medium and low cooling potential across the city, with high cooling towards the north eastern part of the city. Even though Glasgow is famous for its green environments (its name originated from the old Cumbric word Glaschu, meaning 'dear green place' - https://peoplemakeglasgow.com/dear-green-place), most of the green cover fell within the low cooling potential area due to the size and type of $\mathrm{Gl}$. The medium/high cooling pockets of GI were almost non-existent within the deprived areas (Figure 5). 


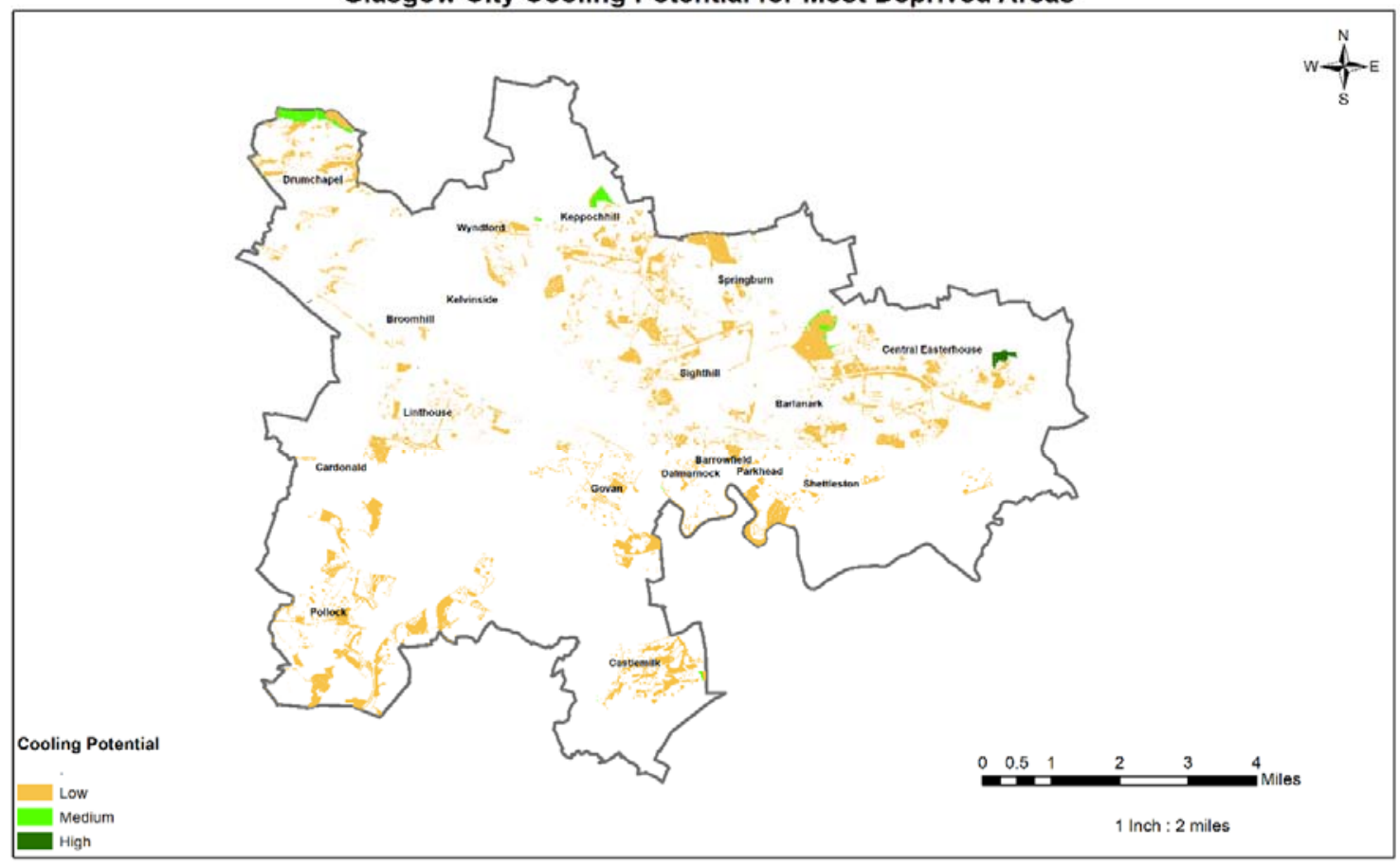

Figure 5: Cooling potential for most deprived areas of Glasgow City

Note: Estimation of deprivation was derived from SIMD data

\subsection{Green Infrastructure Flood Prevention Potential estimation for Glasgow city} The method used to estimate the flood prevention potential for Glasgow city was adapted from the TR55 model of the $i$-Tree tool (https://www.itreetools.org/) which has been developed by the United States Department of Agriculture in order to estimate storm water run-off (NRCS, 1986). The run-off curves generated by TR55 model are dependent on the underlying soil type and extent of vegetation cover (especially grass cover). The soil texture classification for Scotland was sourced from the British Geological Survey (BGS) (https://www.bgs.ac.uk/data/mapViewers/home.html?src=topNav) where the downloaded data was inserted into ArcGIS. As the data was for the whole of Scotland, it was clipped to Glasgow City boundary, our study area. 
Table 7: Soil Texture count for Glasgow City

\begin{tabular}{|l|c|}
\hline \multicolumn{1}{|c|}{ Soil Texture Type } & $\begin{array}{c}\text { Polygon Count (1 Km } \\
\text { Resolution) }\end{array}$ \\
\hline Clay to Sandy Loam & 9 \\
\hline Clayey Loam to Sandy Loam & 148 \\
\hline Loam to Clayey Loam & 1 \\
\hline Loam to Sandy Loam & 2 \\
\hline Sand to Loam & 47 \\
\hline Sand to Sandy Loam & 7 \\
\hline Silt to Silty Loam & 2 \\
\hline Varied, locally Peaty & 22 \\
\hline
\end{tabular}

The $1 \mathrm{Km}$ resolution data in table 7 show that approximately $70 \%$ of Glasgow consists mostly of Clayey loam to Sandy loam which falls under 'Soil Type D' classification (Clay loam, Clay Silty loam, Sandy clay, Silty Clay or Clay) with high runoff potential and very low infiltration rate when thoroughly wet (NRCS, 1986). Together with soil cover data, the extent of grass cover estimated from the PAN 65 data were used to assign flood prevention capability weights (Table 8).

\begin{tabular}{|c|c|c|}
\hline Grass Cover & GI & $\begin{array}{l}\text { Flood } \\
\text { Prevention } \\
\text { Capability }\end{array}$ \\
\hline High grass cover (>75\%) & $\begin{array}{l}\text { - Public parks and gardens } \\
\text { - Community gardens } \\
\text { - Amenity green space } \\
\text { - Natural-Semi Natural green } \\
\text { space }\end{array}$ & 0.8 \\
\hline $\begin{array}{l}\text { Medium grass cover }(50-75 \\
\%)\end{array}$ & $\begin{array}{l}\text { - Play space for children and } \\
\text { teenagers } \\
\text { - Sport areas } \\
\text { - Green corridor } \\
\text { - Other functional green space }\end{array}$ & 0.84 \\
\hline Low grass cover $(<50 \%)$ & - Civic space & 0.89 \\
\hline
\end{tabular}

Once these transformations were made, it was possible to estimate the flood mitigation potential for Glasgow city ('high', 'medium' and 'low') using the top third, middle third and bottom third weighted values (Figure 6). 


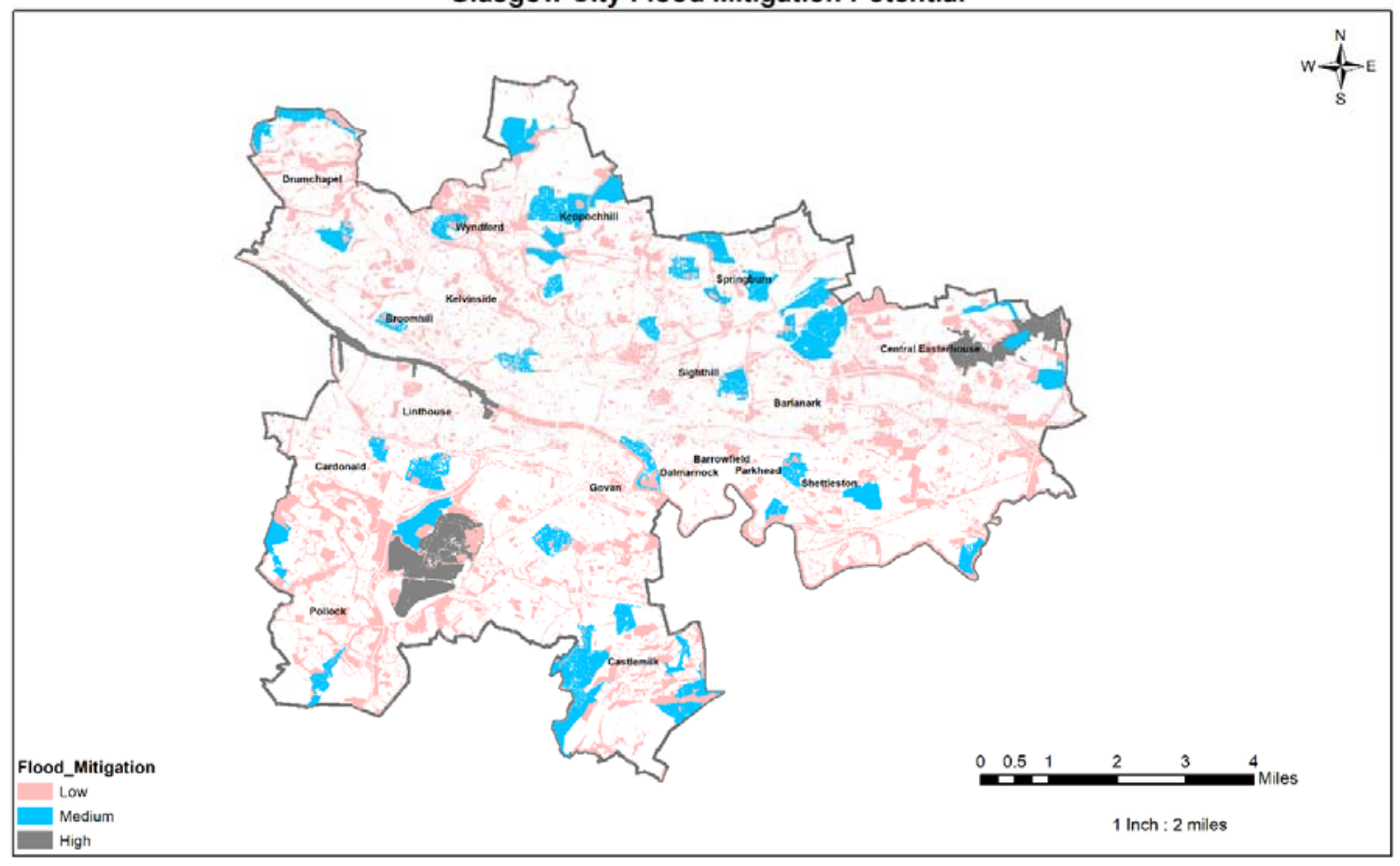

Figure 6: Flood Mitigation Potential Map of Glasgow City

Note: Flood mitigation potential based on Table 8 / Base Map (PAN 65)

In order to extract the GI flood prevention potential estimate for the SIMD 10\% most deprived areas, both SIMD data and flood prevention potential data for Glasgow city edited to show only areas that fall within $10 \%$ most deprived boundary layers (Figure 7). 


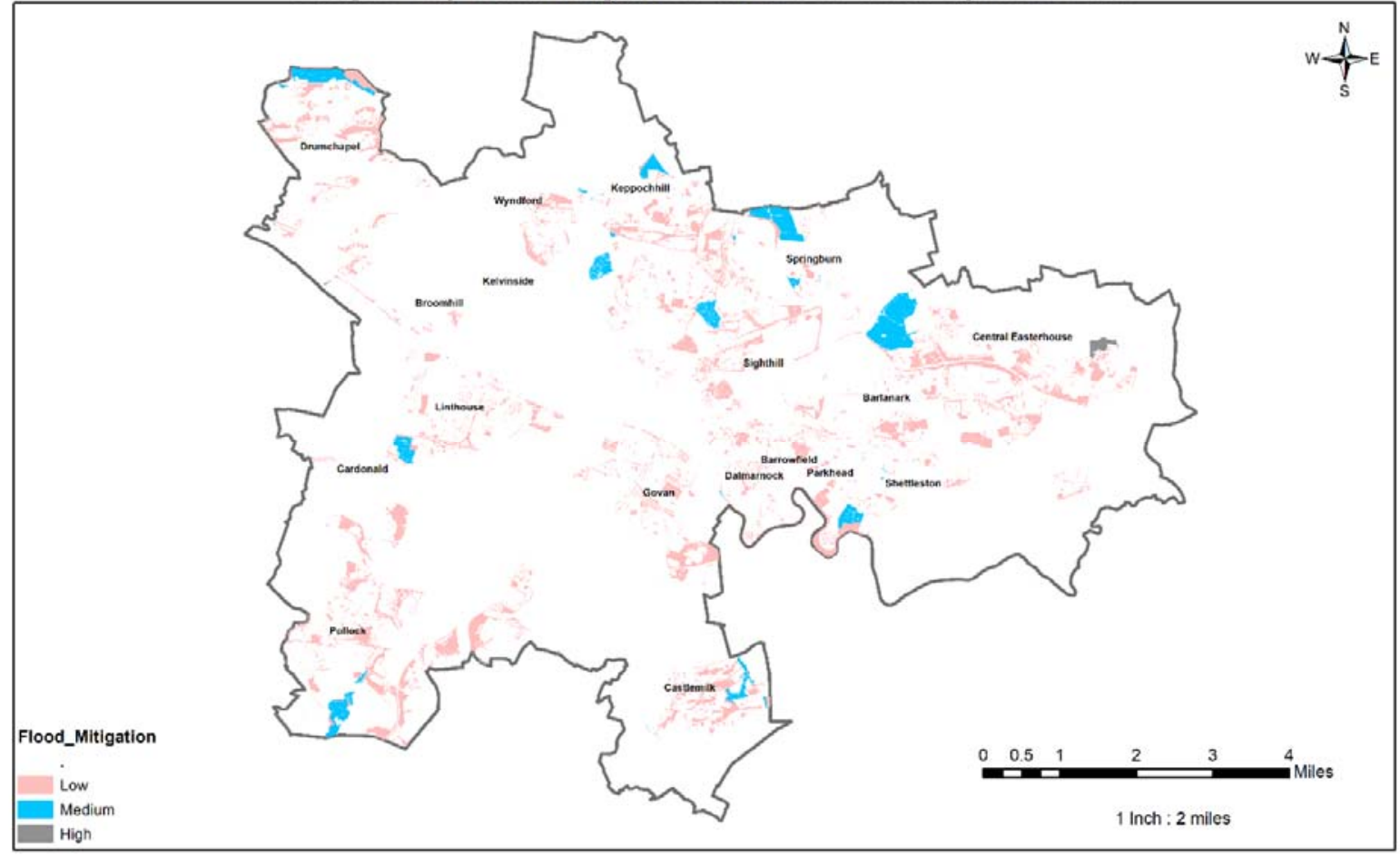

Figure 7: Flood Mitigation potential for the most deprived areas of Glasgow City

Note: Estimation of deprivation was derived from SIMD data and Flood mitigation potential based on Table 8

The flood mitigation potential for Glasgow city provided a more balanced distribution when compared with the cooling potential for Glasgow city. Although the low flood mitigation potential parcels were dominant, there were more pockets capable of providing medium/high flood mitigation across the city and similar trends were also identified within the deprived areas, but there is still room for improving $\mathrm{Gl}$ within and outside the deprived areas.

\subsection{Distribution Green Infrastructure through a climate just lens}

The GI cooling and flood mitigation potential for Glasgow city can broadly be characterised as being fairly distributed on average for the city as a whole but show a mixed picture when analysed for deprived areas. 
Table 9: Cooling Potential Extent

\begin{tabular}{|l|c|c|}
\hline \multicolumn{1}{|c|}{ Effect } & $\begin{array}{c}\text { Glasgow City as a whole (Ha, with percentages } \\
\text { in parenthesis) }\end{array}$ & $\begin{array}{c}\text { Most Deprived } \\
\text { Areas (Ha) }\end{array}$ \\
\hline Low & $3571(76.2 \%)$ & $1137(94.5 \%)$ \\
\hline Medium & $756(16.1 \%)$ & $53(4.4 \%)$ \\
\hline High & $357(7.6 \%)$ & $13(1.1 \%)$ \\
\hline
\end{tabular}

Table 10: Flood mitigation potential extents

\begin{tabular}{|l|l|l|}
\hline \multicolumn{1}{|c|}{ Flood Mitigation } & \multicolumn{1}{c|}{ Potential } & \multicolumn{1}{c|}{ Most Deprived Areas (Ha) } \\
\hline Low & $2954(61.3 \%)$ & $969(78.0 \%)$ \\
\hline Medium & $1356(28.2 \%)$ & $260(20.9 \%)$ \\
\hline High & $507(10.5 \%)$ & $13(1.1 \%)$ \\
\hline
\end{tabular}

In Table 9, the inequity of cooling services provided by Gl in deprived areas is clear. The total area offering low cooling potential for Glasgow city consisted of approximately $3600 \mathrm{Ha}$ of Gl cover, and these were mostly along major roads, streets, gardens, public/private parks, church yards and squares, while the low GI cooling potential cover for the most deprived areas was approximately $1100 \mathrm{Ha}$ (31.8\%). Medium cooling potential GI cover for Glasgow city was approximately 760 ha while that of deprived areas was only $53 \mathrm{Ha}(7 \%)$ which were mostly located in the north eastern/north western parts of the city, and only $13 \mathrm{Ha}$ of GI had high cooling potential within deprived areas compared with357 Ha for Glasgow city.

Similar traits were also observed for flood mitigation potential (Table 10). Although the GI flood mitigation potential for deprived areas had a higher coverage area of $260 \mathrm{Ha}$ when compared with $53 \mathrm{Ha}$ for cooling potential, the GI capable of providing high cooling and high flood mitigation within the deprived area was only $13 \mathrm{Ha}$. This presents a unique problem as our analysis in Table 5 revealed that the distribution of GI within the deprived areas is not equitably distributed. Having understood the benefits $\mathrm{GI}$ can provide, especially in relation to flood mitigation and temperature reduction, such unequal distribution could lead to reduced ecosystem benefits in deprived areas. Our findings of inequitable distribution of $\mathrm{Gl}$ could be represented as a distributive justice problem due to the inability of GI to provide high cooling and flood mitigation in deprived areas

In addition, Glasgow city has the lowest proportion of detached dwellings (4\%) and the highest average density of housing (approximately 17.76 dwellings per hectare) in Scotland, and with a 3.1\% increase in the number of households between 2007 and 2017, Glasgow ranks the $6^{\text {th }}$ lowest in terms of household growth followed by Dundee, South Ayrshire, West Dunbartonshire, Argyll and Bute, and Inverclyde (NRScotland, 2018). With the current rise in temperature, most of the old 
buildings built to withstand extreme cold temperatures are likely to make living in these houses unbearable especially during summer. This could have health consequences, as rising temperature and increased precipitation and humidity could lead to the emergence and transmission of new pests and diseases (WHO, 2009).

Much of the Clyde River valley region of the city is susceptible to sub-surface flooding (SEPA, 2015) (see Fig 1b), could expose members of the community - especially in these deprived areas - to increased disease risk transmitted through water, insects and rodents, as well as, damage to their homes and disruption of the essential supply of medical and health services (WHO, 2009). Without any concrete plans to adapt the existing built environment (homes, hospitals, care homes, schools and prison) to becoming more resilient to an increase in temperature (ASC, 2016a), there is likely to be increased pressure on public health systems to tackle overheating-related illnesses.

An increase in the quantity and accessibility of GI will reduce temperatures and increase resilience to sub-surface flooding prevalent within the study area. Achieving this would create a climate-just environment by increasing resilience and fulfilling one of the climate-just principles. The use of GISbased Gl exploration tools such as the approach presented here could lead to a better, more resilient and equitable communities.

\section{Limitations of the approach}

There are three broad limitations to our approach: data quality, wider validity of assumptions underpinning the study, and scalability. The GI data we used in the present case study was meant to be a spatial audit of the various GI types in the city, not its quality or health. Besides, GI parcels have been bifurcated by roadways and footpaths which in turn reduced the parcel size and therefore under-estimate the potential of GI to provide cooling / flood prevention. The correction of these errors is highly time consuming and would require extensive ground truthing. Furthermore, the GI typology available for Scotland is not fully compatible with Gl typologies typically used for the estimation of ecosystem services (in our case flood prevention and cooling) and this required broad assumptions to be made which may or may not hold for other cities and countries.

Finally, our approach may not be readily transferred to other cities. For example, while the availability of deprivation data in the UK is very good, there are wide variations in the approach even within the UK. Cities in other countries may not have such comprehensive data and there is also a need for more fine-scale resolution of the ecosystem services provided by urban GI (especially their cooling potential and flood prevention potential) and the performance of $\mathrm{Gl}$ under changing climatic conditions (as well as its ability to provide expected levels of ecosystem services) remains unknown. 


\section{Conclusion}

This study has shown that deprived communities within Glasgow city would most likely be more negatively impacted in the event of a heatwave or flooding incident than residents in affluent areas. The medium to high cooling/flood mitigation extent per hectare for deprived areas was approximately $66 / 273 \mathrm{Ha}$ respectively which is quite low when compared with the rest of the city where Gl cooling/flood mitigation potential extent was 1113/1863 Ha respectively (Tables 9 and 10). Although there is reasonable GI within the deprived areas to mitigate sub-surface flooding, the same cannot be said for the capability of GI to mitigate overheating within the deprived communities, and a heatwave is likely to impact negatively on these communities at unprecedented levels leaving them highly exposed to climate risk impacts. Furthermore, the personal, environmental and social attributes (such as income, insurance, house and personal mobility and others) of these deprived communities could further hinder their ability to respond and recover from climate impacts.

We have also been able to show that intervention especially within these deprived areas would yield the greatest climate-just and equitable impact as these areas may not be economically equipped to repair the climate impact damages or get adequate help, especially when we consider that Glasgow city has the highest average density dwelling per hectare for Scotland with very few modern building being built.

Improved data quality (especially in terms of spatial extent, health and quality of GI data) and a more robust (evidence based) assumption valid for the local context would increase confidence in our approach.

\section{References}

Adaptation Scotland (2017) Our Vision for Glasgow and the Clyde Valley. Available at: https://www.adaptationscotland.org.uk/application/files/5914/7222/2922/CRCVisonFINAL.pd $f$ (Accessed: 15 June 2017).

Andy Dengel, Mich Swainson, David Ormandy, Veronique Ezratty (2016) 'Overheating in dwellings Guidance Document The BRE Centre for Resilience'. Available at: https://www.bre.co.uk/filelibrary/Briefing papers/116885-Overheating-Guidance-v3.pdf.

ASC (2012) Adaptation Scotland, The Climate Ready Clyde Project, Resilient Cities Webinar. Available at: http://resilient-cities.iclei.org/fileadmin/sites/resilient-

cities/files/Resilient_Cities_2012/Digital_Congress_Proceedings/AB_Resilient_cities_webinar_ 151112.pdf.

ASC (2016a) Scottish Climate Change Adaptation Programme: An independent assessment for the Scottish Parliament. Available at: https://www.theccc.org.uk/wpcontent/uploads/2016/09/Scottish-Climate-Change-Adaptation-Programme-An-independentassessment-CCC-September-2016.pdf.

ASC (2016b) 'UK Climate Change Risk Assessment 2017 Evidence Report: Key messages from the Synthesis Report'. Available at: https://www.theccc.org.uk/wpcontent/uploads/2016/07/CCRA-Synthesis-Report-Key-Messages-fact-sheet-1.pdf. 
ASC (2016c) 'UK Climate Change Risk Assessment 2017 Evidence Report - Summary for Scotland', Adaptation Sub-Committee of the Committee on Climate Change, London. Available at: https://www.theccc.org.uk/wp-content/uploads/2016/07/UK-CCRA-2017-Scotland-NationalSummary.pdf.

ASC (2016d) UK Climate Change Risk Assessment 2017 Synthesis Report: priorities for the next 5 years. London. Available at: https://www.theccc.org.uk/wp-content/uploads/2016/07/UKCCRA-2017-Synthesis-Report-Committee-on-Climate-Change.pdf.

ASC (2017) The Hidden Problem of overheating - Committee on Climate Change, Committee on Climate Change. Available at: www.theccc.org.uk/2017/08/08/hidden-problrm-overheating/ (Accessed: 23 September 2017).

Carter, J. G. et al. (2018) 'Adapting cities to climate change - exploring the flood risk management role of green infrastructure landscapes', Journal of Environmental Planning and Management. Taylor \& Francis, 61(9), pp. 1535-1552. doi: 10.1080/09640568.2017.1355777.

ClimateXChange. (2016) Indicators and trends: monitoring climate change adaptation. Available at: http://www.climatexchange.org.uk/files/8614/7558/3595/BB13_Impermeable_surfaces.pdf.

Clydeplan (2015) Strategic Development Plan Main Issues Report - Background Report 11. Available at: https://www.clydeplan-sdpa.gov.uk/files/BR11.pdf.

Committee on Climate Change (2017) 'Progress in preparing for climate change', 2017 Report to Parliament, (June). Available at: https://www.theccc.org.uk/wpcontent/uploads/2017/06/2017-Report-to-Parliament-Progress-in-preparing-for-climatechange.pdf.

Duncan, J. M. A. et al. (2019) 'Turning down the heat: An enhanced understanding of the relationship between urban vegetation and surface temperature at the city scale', Science of the Total Environment. Elsevier B.V., 656, pp. 118-128. doi: 10.1016/j.scitotenv.2018.11.223.

Emmanuel, R. and Loconsole, A. (2015) 'Green infrastructure for overheating adaptation in Glasgow', Landscape and Urban Planning. 138, pp. 71-86

GCVGreenNetwork (2014) 'Green Network Opportunities Mapping Glasgow City', (February).

Gill, S. E. et al. (2007) 'Adapting cities for climate change: The role of the green infrastructure', Built Environment, 33(1), pp. 115-133. doi: 10.2148/benv.33.1.115.

Glasgow City Council (2017) 'A Local Climate Impacts Profile for Glasgow City Council'.

Guerreiro, S. B. et al. (2018) 'Future heat-waves, droughts and floods in 571 European cities', Environmental Research Letters, 13, p. 034009. doi: 10.1088/1748-9326/aaaad3.

Hall, J. M., Handley, J. F. and Ennos, A. R. (2012) 'The potential of tree planting to climate-proof high density residential areas in Manchester, UK', Landscape and Urban Planning. Elsevier B.V., 104(3-4), pp. 410-417. doi: 10.1016/j.landurbplan.2011.11.015.

Hiemstra, J. A., Saaroni, H. and Amorim, J. H. (2017) 'The Urban Heat Island: Thermal Comfort and the Role of Urban Greening', in Springer, pp. 7-19. doi: 10.1007/978-3-319-50280-9_2.

Hislop, M. and Corbett, A. (2018) 'Green Infrastructure Policies in the CSGN A Review of Local Authority Policies on Green Infrastructure in Built Development', (April).

Kabisch, N. and van den Bosch, M. A. (2017) 'Urban Green Spaces and the Potential for Health Improvement and Environmental Justice in a Changing Climate', in Kabisch, N. et al. (eds) Nature-Based Solutions to Climate Change Adaptation in Urban Areas: Linkages between Science, Policy and Practice. Cham: Springer International Publishing, pp. 207-220. doi: 10.1007/978-3-319-56091-5_12.

Kabisch, N. and Haase, D. (2014) 'Green justice or just green? Provision of urban green spaces in Berlin, Germany', Landscape and Urban Planning. Elsevier B.V., 122, pp. 129-139. doi: 10.1016/j.landurbplan.2013.11.016.

Lindley, S. et al. (2011) 'Climate change, justice and vulnerability', Joseph Rowntree Foundation, (November), pp. 1-180. Available at: http://nationalfloodforum.org.uk/wpcontent/uploads/JRF-climate-change-social-vulnerability-full.pdf.

McLeod, R. S., Hopfe, C. J. and Kwan, A. (2013) 'An investigation into future performance and 
overheating risks in Passivhaus dwellings', Building and Environment, pp. 189-209. doi: 10.1016/j.buildenv.2013.08.024.

Middel, A., Chhetri, N. and Quay, R. (2015) 'Urban forestry and cool roofs: Assessment of heat mitigation strategies in Phoenix residential neighborhoods', Urban Forestry and Urban Greening. Elsevier GmbH., 14(1), pp. 178-186. doi: 10.1016/j.ufug.2014.09.010.

NRCS (1986) 'Urban Hydrology for Small', Urban Hydrology for Small Watersheds, (210-VI-TR-55), p. 164. doi: Technical Release 55.

NRScotland (2018) Estimates of Households and Dwellings in Scotland , 2017. Available at: https://www.nrscotland.gov.uk/files//statistics/household-estimates/2017/house-est-17publication.pdf.

O'Brien, L. et al. (2017) 'Social and Environmental Justice: Diversity in Access to and Benefits from Urban Green Infrastructure - Examples from Europe', in Springer, pp. 153-190. doi: 10.1007/978-3-319-50280-9_15.

Lawrebce-Race, Gay (2010) 'Overheating', in How to Manage Overheating in Buildings - A Practical Guide to Improving Summertime Comfort in Buildings - CIBSE Knowledge Series: KS16. London: The Chartered Institution of Building Services Engineers (CIBSE knowledge series; KS16), p. 42. Available at: https://www.cibse.org/Knowledge/knowledgeitems/detail?id=a0q2000000817gR.

Scottish Government (2016) 'SIMD16 Technical Notes', available at: https://www2.gov.scot/Resource/0050/00504822.pdf

Scottish Government (2020) 'The Scottish Index of Multiple Deprivation (SIMD) 2020', . ISBN: 978-183960-271-9. https://www.gov.scot/publications/scottish-index-multiple-deprivation-2020/

SEPA (2015) Flood Risk Management Strategy Clyde and Loch Lomond. Available at: http://apps.sepa.org.uk/FRMStrategies/pdf/lpd/LPD_11_Full.pdf.

SNIFFER (2017) 'Climate Ready Clyde Risk and Opportunity Assessment Workshop', (November). Available at: http://climatereadyclyde.org.uk/wp-content/uploads/2018/06/CRC-Risk-andOpportunity-Workshop_8-November-2017_FINAL_For-circulation.pdf.

The Scottish Government (2008) 'Planning and open space', pp. 1-28.

The Scottish Government (2011) 'GREEN INFRASTRUCTURE Design and Placemaking', pp. 1-28. doi: 78-1-78045-351-4.

Thomas, H. and Nisbet, T. R. (2007) 'An assessment of the impact of floodplain woodland on flood flows', Water and Environment Journal, 21(2), pp. 114-126. doi: 10.1111/j.17476593.2006.00056.x.

WHO (2009) 'Protecting health from climate change: connecting science, policy and people', World Health, p. 36. Available at: http://whqlibdoc.who.int/publications/2009/9789241598880_eng.pdf\%5Cnhttp://apps.who.i nt/iris/bitstream/10665/44246/1/9789241598880_eng.pdf.

World Health Organization (2007) 'Housing, Energy and Thermal Comfort: A review of 10 countries within the WHO European Region', World Health Organization, pp. 1-27.

Xiao, Q. and McPherson, E. G. (2003) 'Rainfall interception by Santa Monica's municipal urban forest', Urban Ecosystems, 6(4), pp. 291-302. doi: 10.1023/b:ueco.0000004828.05143.67.

Zardo, L. et al. (2017) 'Estimating the cooling capacity of green infrastructures to support urban planning', Ecosystem Services, 26, pp. 225-235. doi: 10.1016/j.ecoser.2017.06.016.

Zölch, T. et al. (2016) 'Using green infrastructure for urban climate-proofing: An evaluation of heat mitigation measures at the micro-scale', Urban Forestry and Urban Greening. Elsevier GmbH., 20, pp. 305-316. doi: 10.1016/j.ufug.2016.09.011. 